\title{
Activation of a $\mathrm{Si}=\mathrm{Si}$ Bond by
}

\author{
$\eta^{1}$-Coordination to a Transition Metal
}

Thi-loan Nguyen, David Scheschkewitz*

\section{SUPPLEMENTARY MATERIAL}

S-1 Content

S-2 Experimental Details for $\mathbf{2}$ and $\mathbf{3}$

S-5 NMR spectra of 2

S-10 NMR spectra of 3

[*] Dr. D. Scheschkewitz

Bayerische Julius-Maximilians Universität

Institut für Anorganische Chemie

Am Hubland

D-97074 Würzburg, Germany

Fax: ++49(0)931/888-4623

E-Mail: scheschkewitz@mail.uni-wuerzburg.de 


\section{Experimental details}

\section{Synthesis of zirconocenedisilenide $\mathbf{2}$}

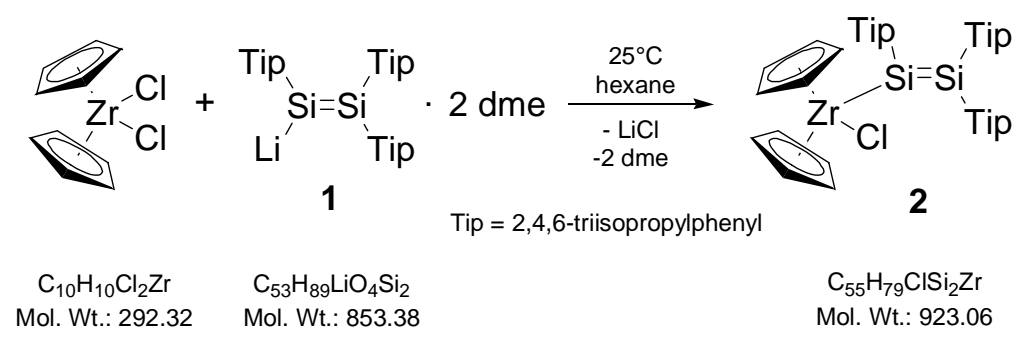

At $-196^{\circ} \mathrm{C}$ approx. $20 \mathrm{~mL}$ of hexane are condensed to a mixture of $1.00 \mathrm{~g}(1.17 \mathrm{mmol})$ disilenide $\mathbf{1}$ and $0.36 \mathrm{~g} \quad(1.23 \mathrm{mmol})$ finely ground, freshly sublimed zirconocenedichloride. The resulting suspension is brought to ambient temperature and stirred for 3h. The resulting intensely green solution is filtered under argon and evaporated to dryness in vacuum yielding $1.05 \mathrm{~g}(97 \%)$ of 2 as a green solid of near spectroscopic purity.

${ }^{1} \mathbf{H}$ NMR $\left(\mathrm{C}_{6} \mathrm{D}_{6}, 500 \mathrm{MHz}, 2^{\circ} \mathrm{C}\right) \delta$ 7.11, 7.07, 6.97 (s, 2H each, ArH), 5.91 (s, 10H, $\mathrm{CpH}$ ), 4.23, 4.10 (br., 3.4 H, i-Pr-CH), 3.55 (hept., 2H, i-Pr-CH), 2.79, 2.73, 2.64 (hept., 1H each, i-Pr-CH), 1.46, 1.39, 1.33 (br.), 1.20, 1.14, 1.08 (d, 54H altogether, i-Pr- $\mathrm{CH}_{3}$ ), 0.87 (t, hexane) $\mathrm{ppm}$. The integration of some signals is inaccurate due to a) residual hexane, b) coalescence of some signals, c) slow relaxation of Cp protons.

${ }^{13} \mathrm{C}$ NMR $\left(\mathrm{C}_{6} \mathrm{D}_{6}, 125 \mathrm{MHz}, 25^{\circ} \mathrm{C}\right) \delta 155.14$ (br.), 154.89, 154.73, 151.46, 150.42, 148.96, 142.24, 140.34, 138.14 (Ar-C), 122.64, 122.28, 122.02 (Ar-CH), 111.08 (Cp-C), 38.30, 37.23, 36.17, 34.74, 34.68, 34.33 (i-Pr-CH), 31.93 (hexane), 26.43 (br.), 24.86, 24.13, 23.86 (i-Pr- $\mathrm{CH}_{3}$ ), 23.01, 14.33 (hexane) ppm. Cp-containing impurities of 
unknown constitution give rise to additional signals of low intensity at: 115.69, 114.12, 100.79, 98.35 ppm. The rearrangement product $\mathbf{3}$ is detectable in trace amounts.

${ }^{29} \mathrm{Si}$ NMR $\left(\mathrm{C}_{6} \mathrm{D}_{6}, 99 \mathrm{MHz}, 2^{\circ} \mathrm{C}\right) \delta 152.5\left(\mathrm{Cp}_{2} \mathrm{ZrSi}\right), 116.8\left(\mathrm{SiAr}_{2}\right) \mathrm{ppm}$.

UV-Vis (hexane, $25^{\circ} \mathrm{C}$ ) $\lambda_{\max }(\varepsilon) 715$ (approx. 7000), 416 (approx. 3000) nm. The exact determination of the $\varepsilon$ was hampered by the difficulties to produce sufficiently diluted solutions of $\mathbf{2}$ without some decomposition and/or rearrangement to 3 .

\section{$\underline{\text { Rearrangement of zirconocenedisilenide } 2 \text { to silylzirconocene } 3}$}

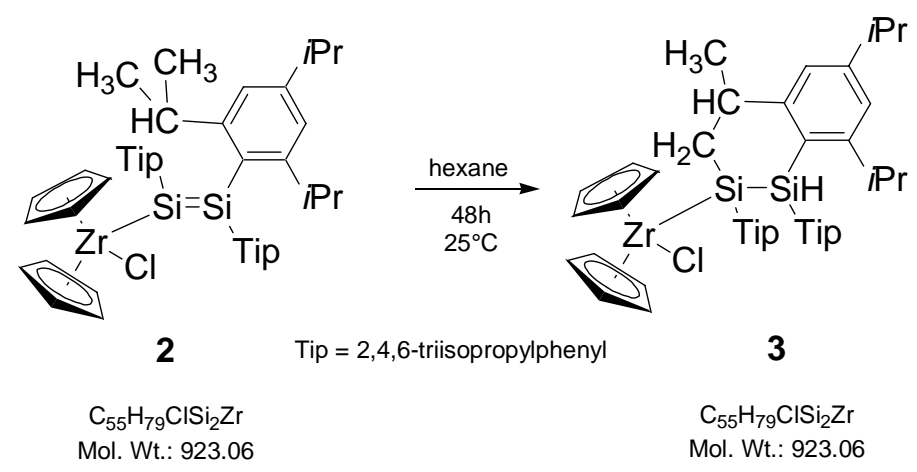

A solution of $0.89 \mathrm{~g}(0.96 \mathrm{mmol})$ of 2 in $10 \mathrm{~mL}$ of hexane is kept at ambient temperature for $48 \mathrm{~h}$ gradually changing color from green to red during that period. Cooling to $0^{\circ} \mathrm{C}$ yielded $0.51 \mathrm{~g}$ (57\%) of l,l-3 as a micro-crystalline red solid of near spectroscopic purity.

Mp. $154^{\circ} \mathrm{C}$ (dec.)

${ }^{1} \mathbf{H}$ NMR $\left(\mathrm{C}_{6} \mathrm{D}_{6}, 500 \mathrm{MHz}, 25^{\circ} \mathrm{C}\right) \delta$ 7.20, 7.11, 7.05 (br.), 6.93, 6.91 (s, 6H, ArH), 5.914, 5.910 (s, 10H, CpH), 5.74 (d, 1H, ${ }^{4} \mathrm{~J}=2.44 \mathrm{~Hz}, \mathrm{SiH}$ ), 3.83, 3.66, 3.60, 3.35, 2.78, 2.73, 2.62 (hept., 9H, i-Pr-CH), 2.31 (pseudo-dt, $1 \mathrm{H},{ }^{2} \mathrm{~J}=15.37 \mathrm{~Hz}, \mathrm{SiCH}_{2}$ ), 2.18 (dd, dt, $1 \mathrm{H},{ }^{2} \mathrm{~J}$ = $15.49 \mathrm{~Hz}, \mathrm{SiCH}_{2}$ ), 1.64, 1.59, 1.51, 1.48 (d, 15H, i-Pr-CH $\mathrm{CH}_{3}$, 1.44, 1.36 (br., 9H, i-Pr- 
$\left.\mathrm{CH}_{3}\right), 1.25,1.20,1.19,1.17,1.10,1.09,0.90,0.81$ (d, 27H, i-Pr-CH $\mathrm{CH}_{3}$ ppm. A small signal at $6.02 \mathrm{ppm}$ is tentatively attributed to the Cp-rings of trace amounts of the other diastereomers of 3 .

${ }^{13} \mathrm{C}$ NMR $\left(\mathrm{C}_{6} \mathrm{D}_{6}, 125 \mathrm{MHz}, 25^{\circ} \mathrm{C}\right) \delta 156.63$ (br.), 156.30, 155.45 (br.), 155.23, 154.60, 152.16, 150.39, 148.85, 148.24, 137.32, 134.85, 130.35 (Ar-C), 126.83, 122.94, 122.20 (br.), 121.64, 121.48 (br.), 120.67 (Ar-CH), 111.62, 111.48 (Cp-C), 38.88, 36.00 (br.), 35.10, 34.67, 34.57, 34.31, 34.12, 33.45 (br.), 33.06 (i-Pr- $\mathrm{CH}$ ), 31.91 (hexane), 31.06 (iPr- $\mathrm{CH}_{3}$ ), 30.67 ( $\mathrm{SiCH}_{2}$ ), 28.64 (br.), 27.39 (br.), 27.27 (br.), 26.36, 26.05, 25.48, 25.40, 24.84, 24.54, 24.30, 24.13, 24.05, 24.03, 24.00, 23.91 (i-Pr- $\mathrm{CH}_{3}$ ), 23.00, 14.32 (hexane) ppm. Comparatively small signals at 115.59, 114.11, $113.10 \mathrm{ppm}$ are tentatively attributed to the Cp-rings of trace amounts of the other diastereomers of 3

${ }^{29} \mathrm{Si} \mathrm{NMR}\left(\mathrm{C}_{6} \mathrm{D}_{6}, 99 \mathrm{MHz}, 25^{\circ} \mathrm{C}\right) \delta-8.4\left(\mathrm{SiCH}_{2} \mathrm{Ar}\right),-46.1\left(\mathrm{SiHAr}_{2}\right) \mathrm{ppm}$.

UV-Vis (hexane, $\left.25^{\circ} \mathrm{C}\right) \lambda_{\max }(\varepsilon) 490(1400) \mathrm{nm}$.

Combustion analysis $\left(\mathrm{C}_{55} \mathrm{H}_{79} \mathrm{ClSi}_{2} \mathrm{Zr}\right)$ : calc. C 71.56, $\mathrm{H}$ 8.63, found C 71.42, H 8.26 
${ }^{1} \mathrm{H}$ NMR of $\mathbf{2}$

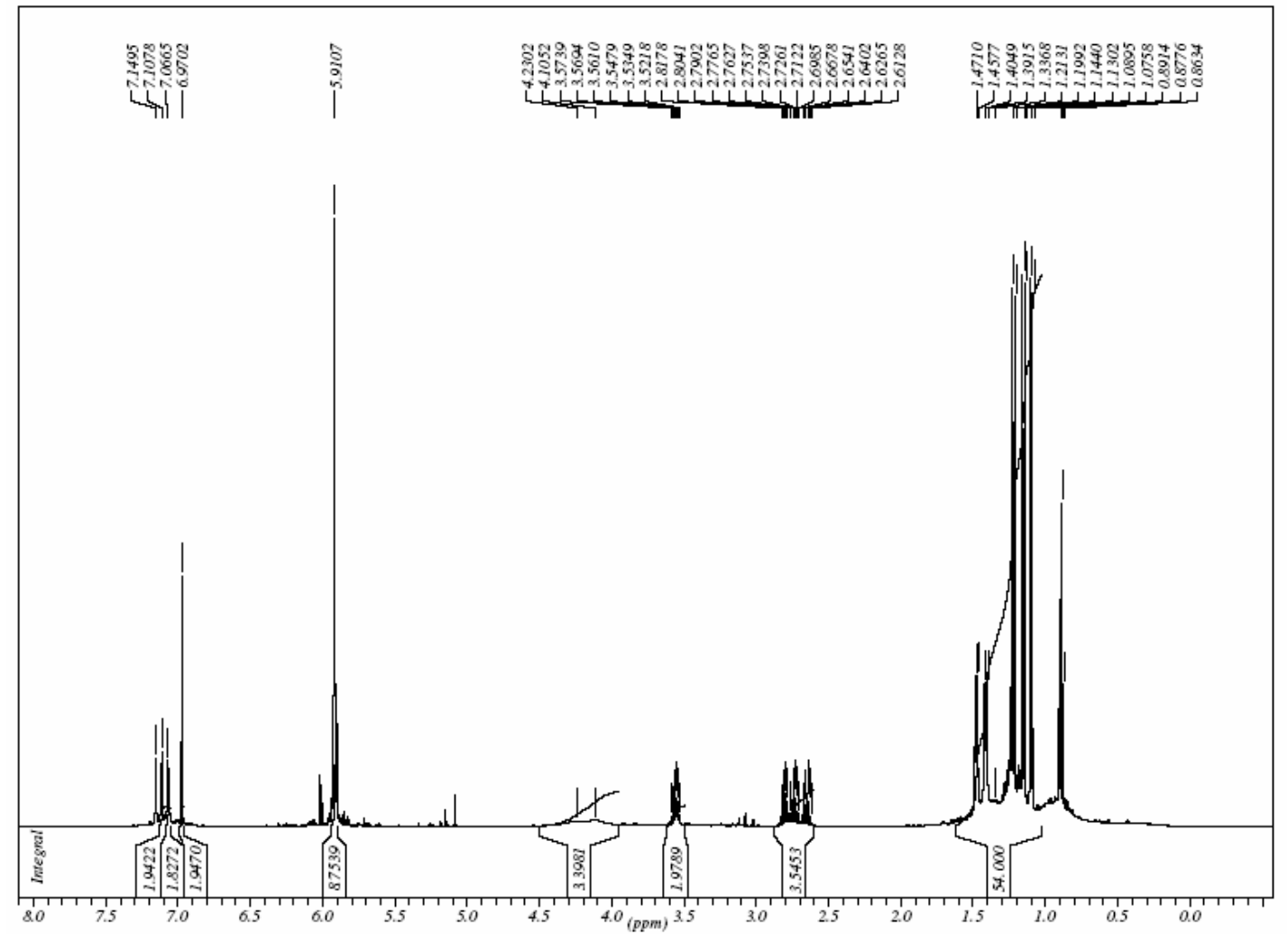

${ }^{1} \mathrm{H}$ NMR of $\mathbf{2}$

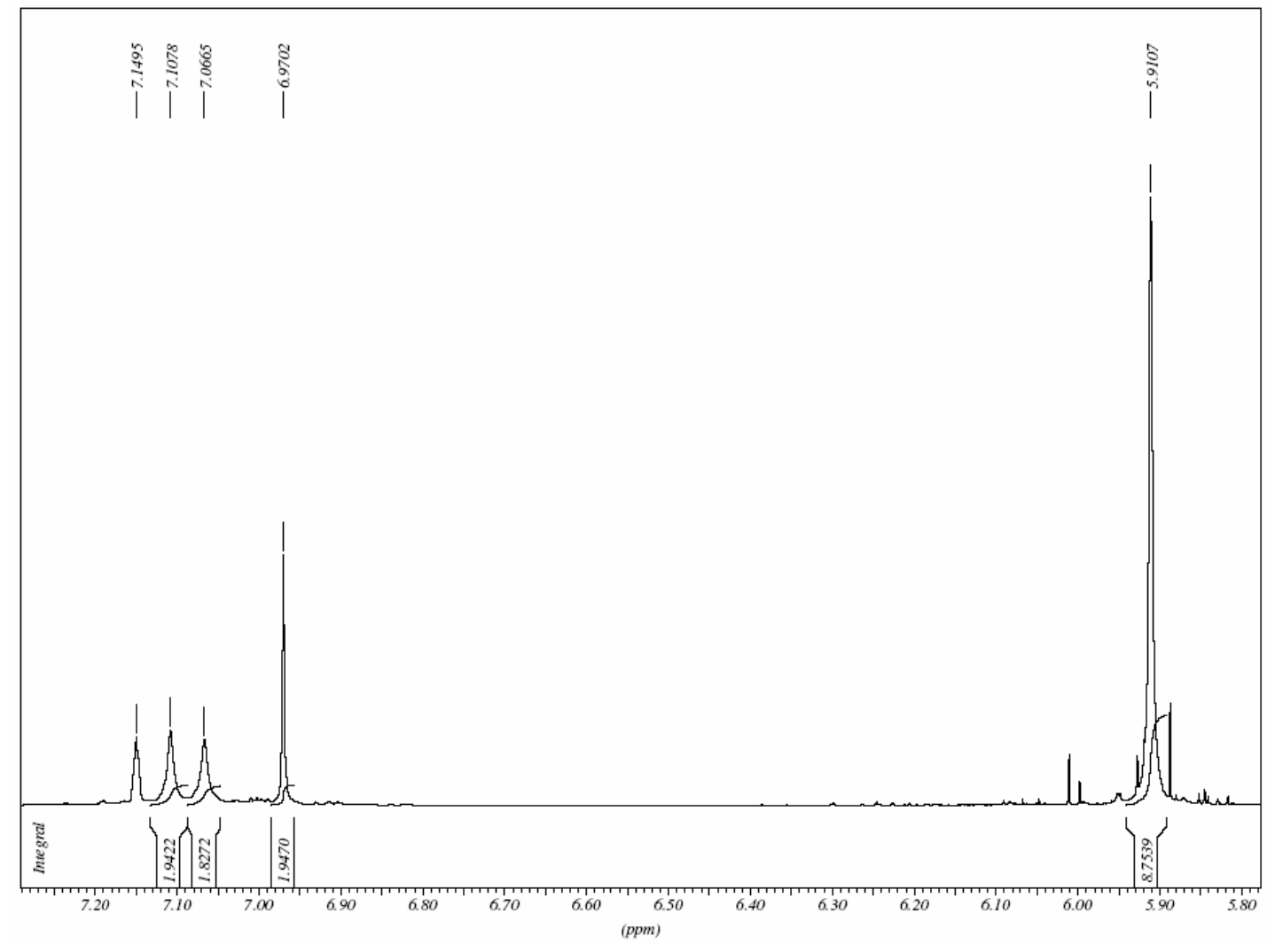


${ }^{1} \mathrm{H}$ NMR of $\mathbf{2}$

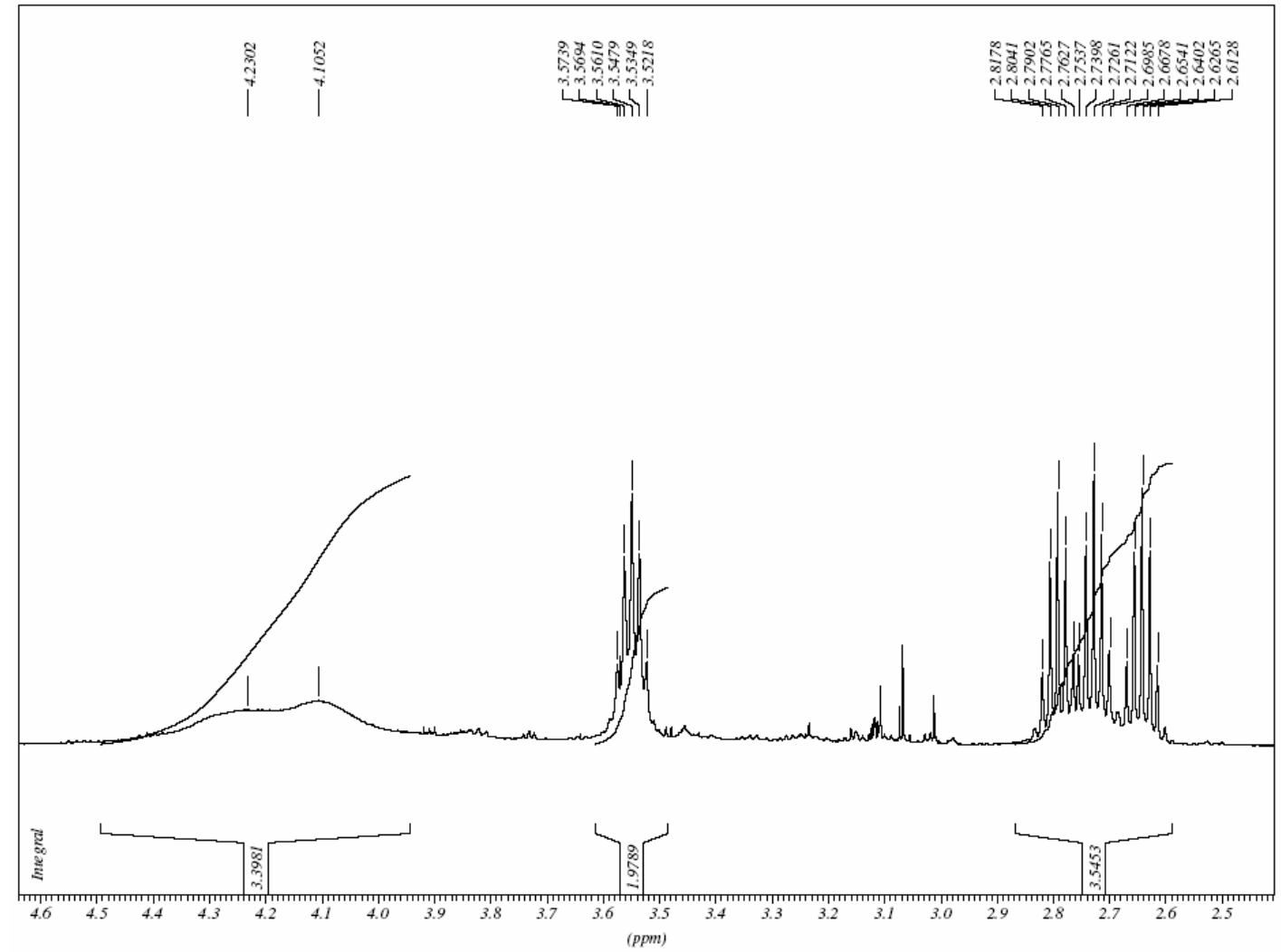

${ }^{1} \mathrm{H}$ NMR of $\mathbf{2}$

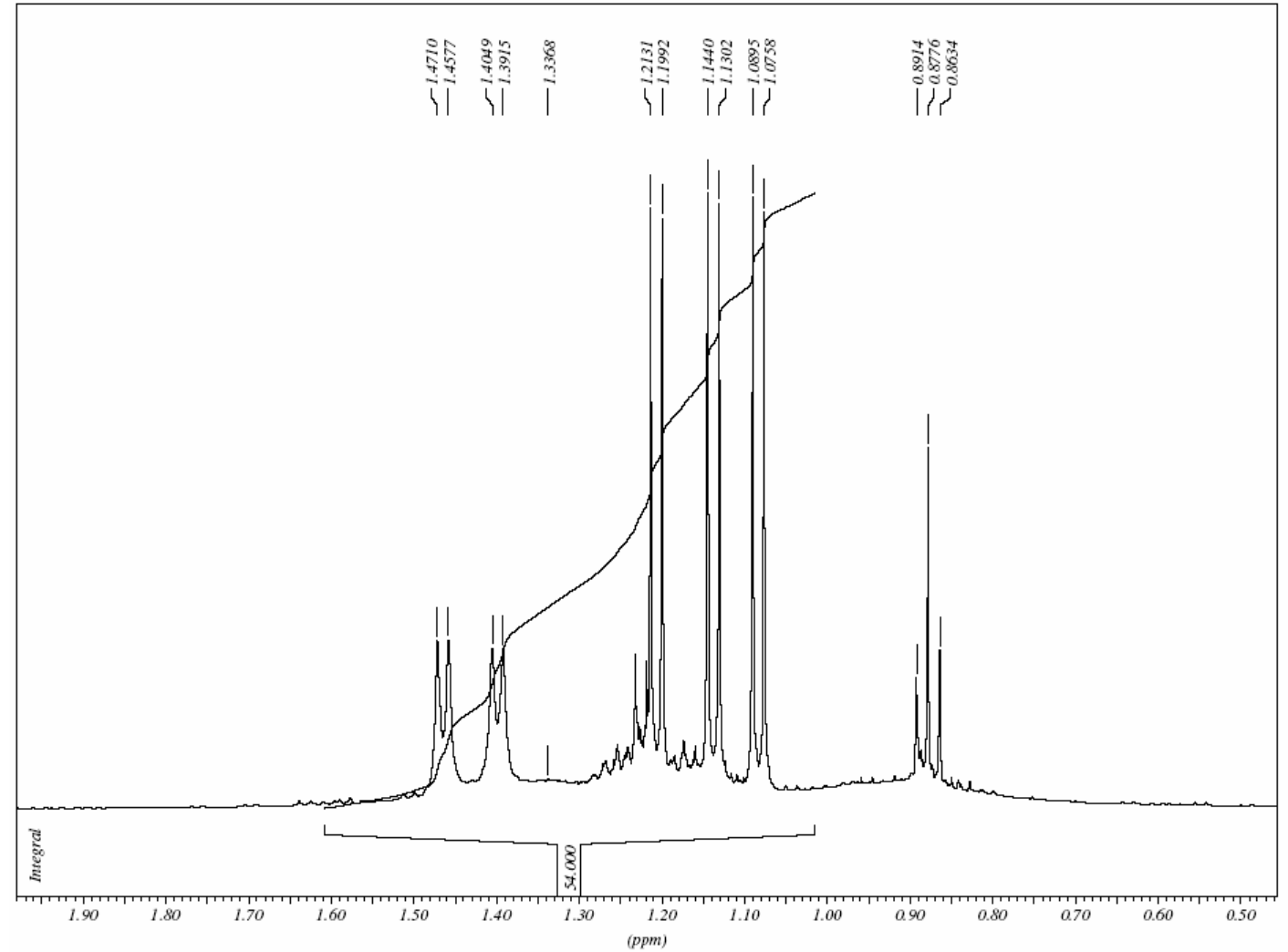




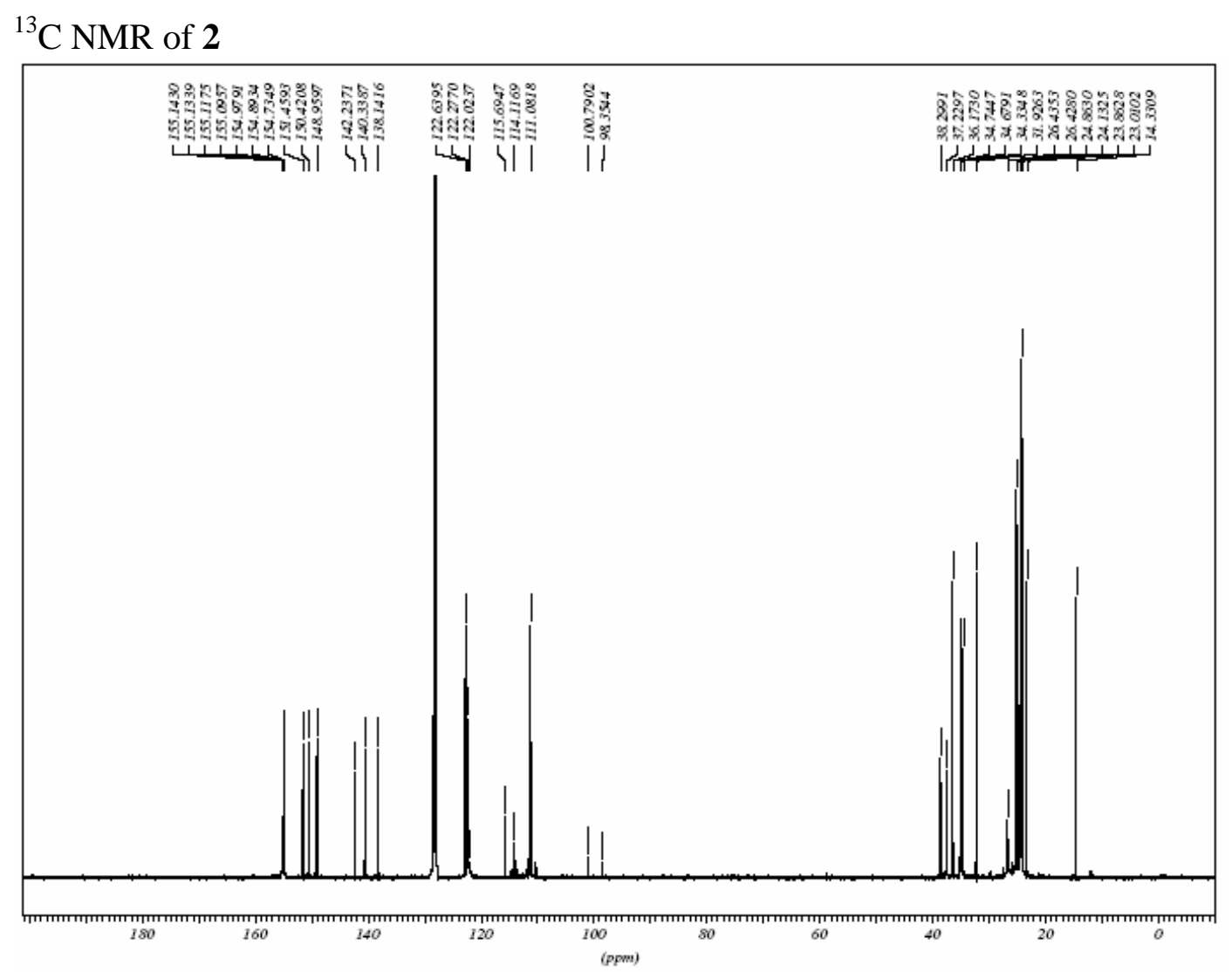

${ }^{13} \mathrm{C}$ NMR of 2

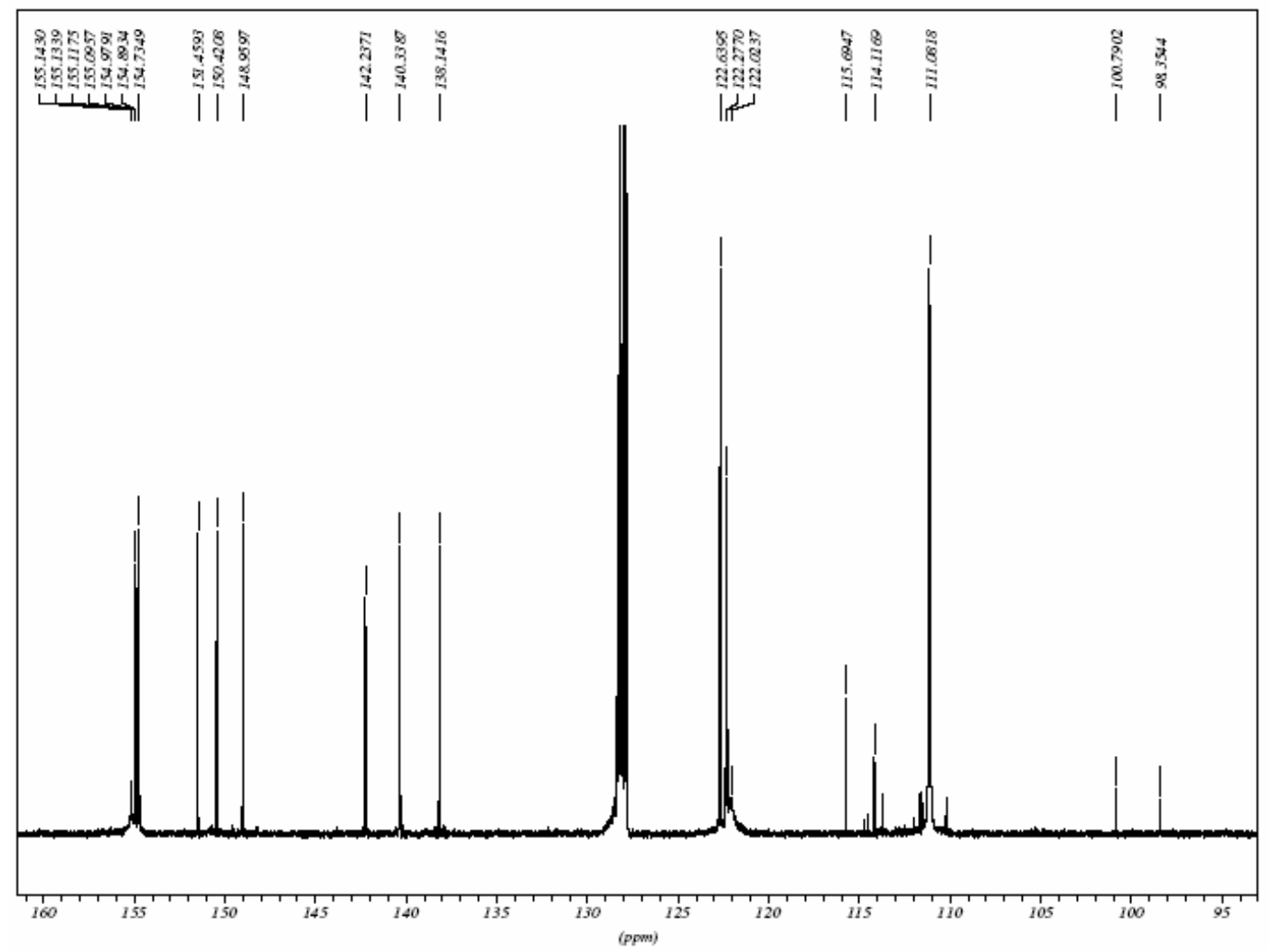




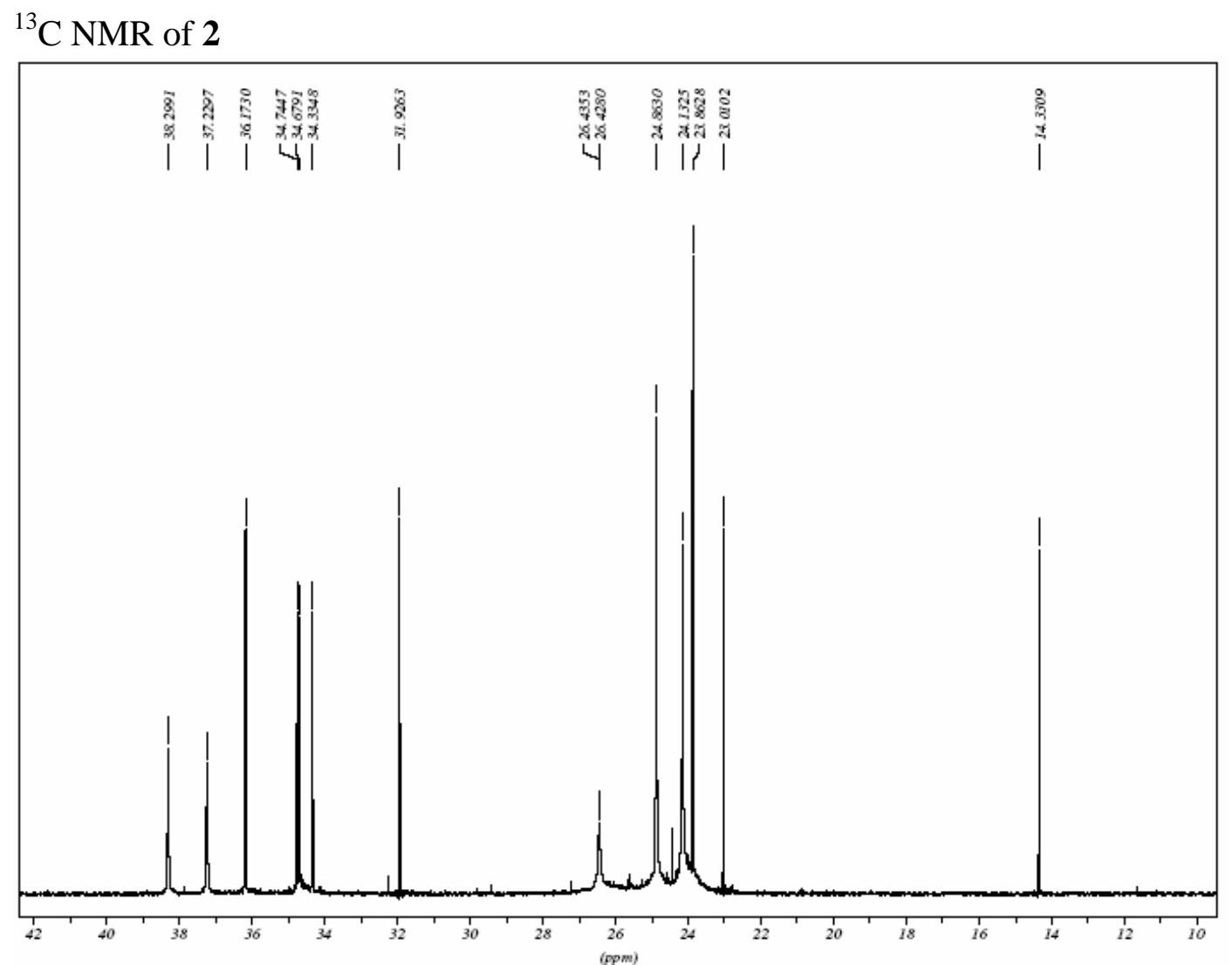

\section{${ }^{29}$ Si NMR of 2}

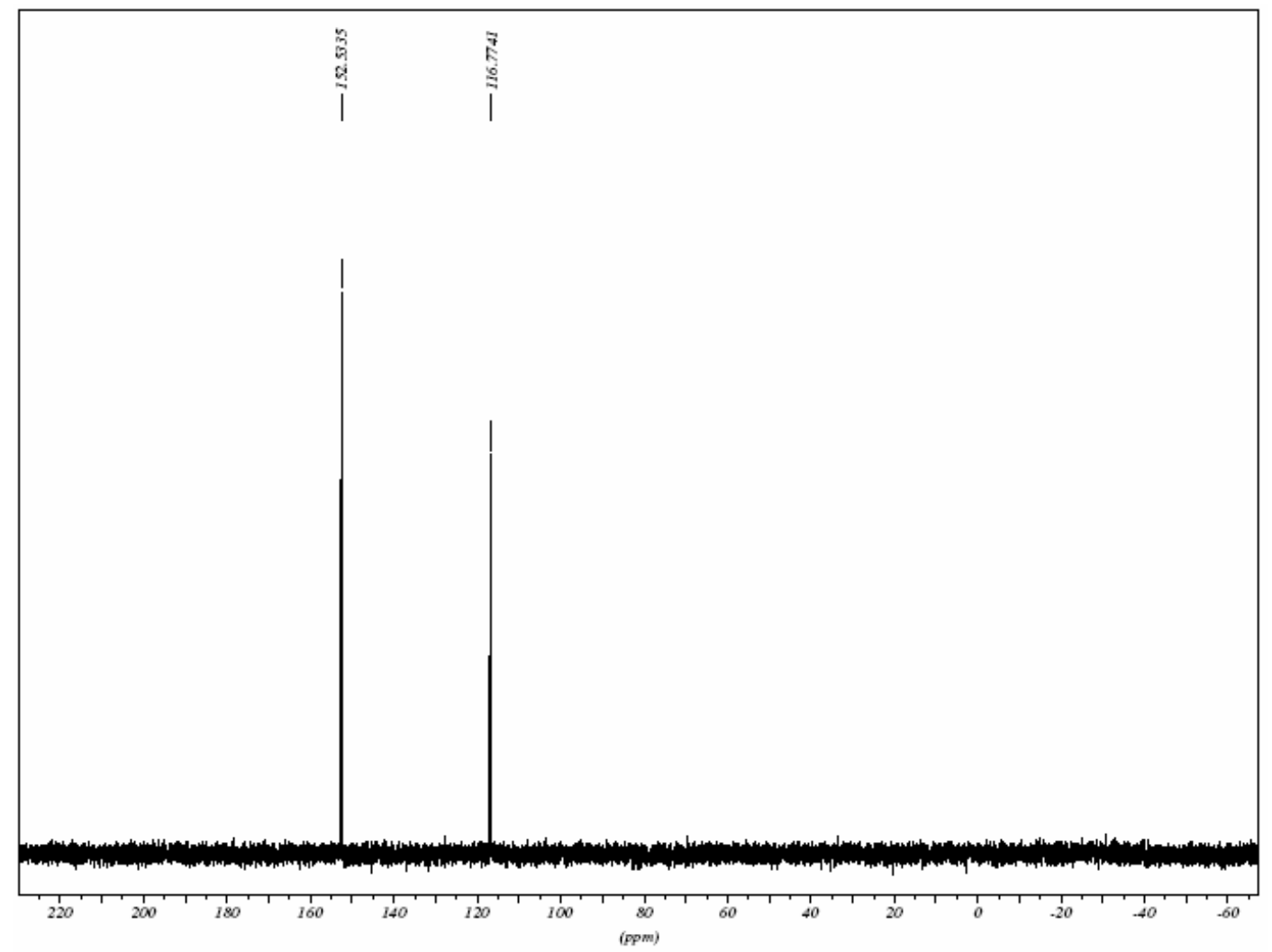




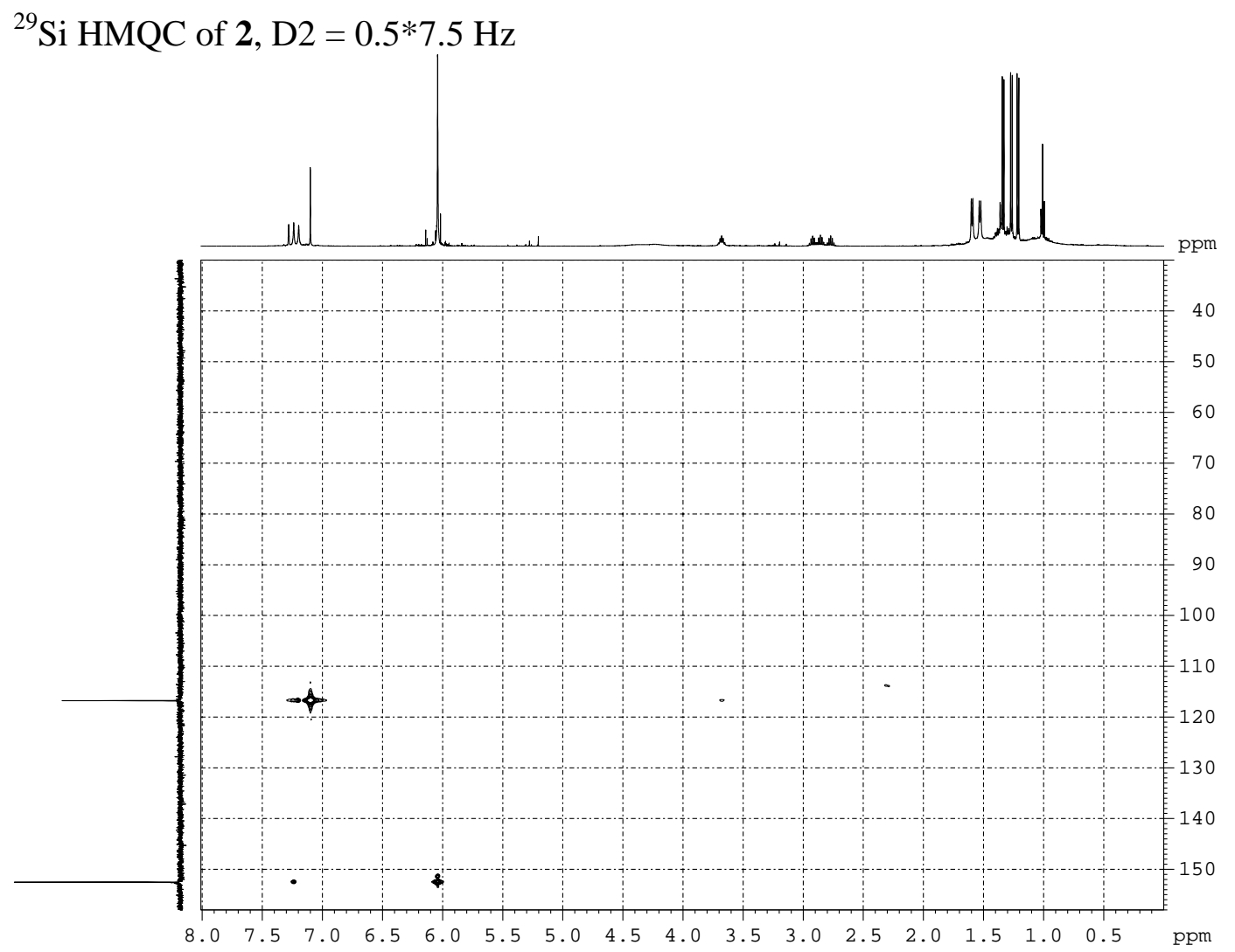

\section{${ }^{29}$ Si HMQC of 2}

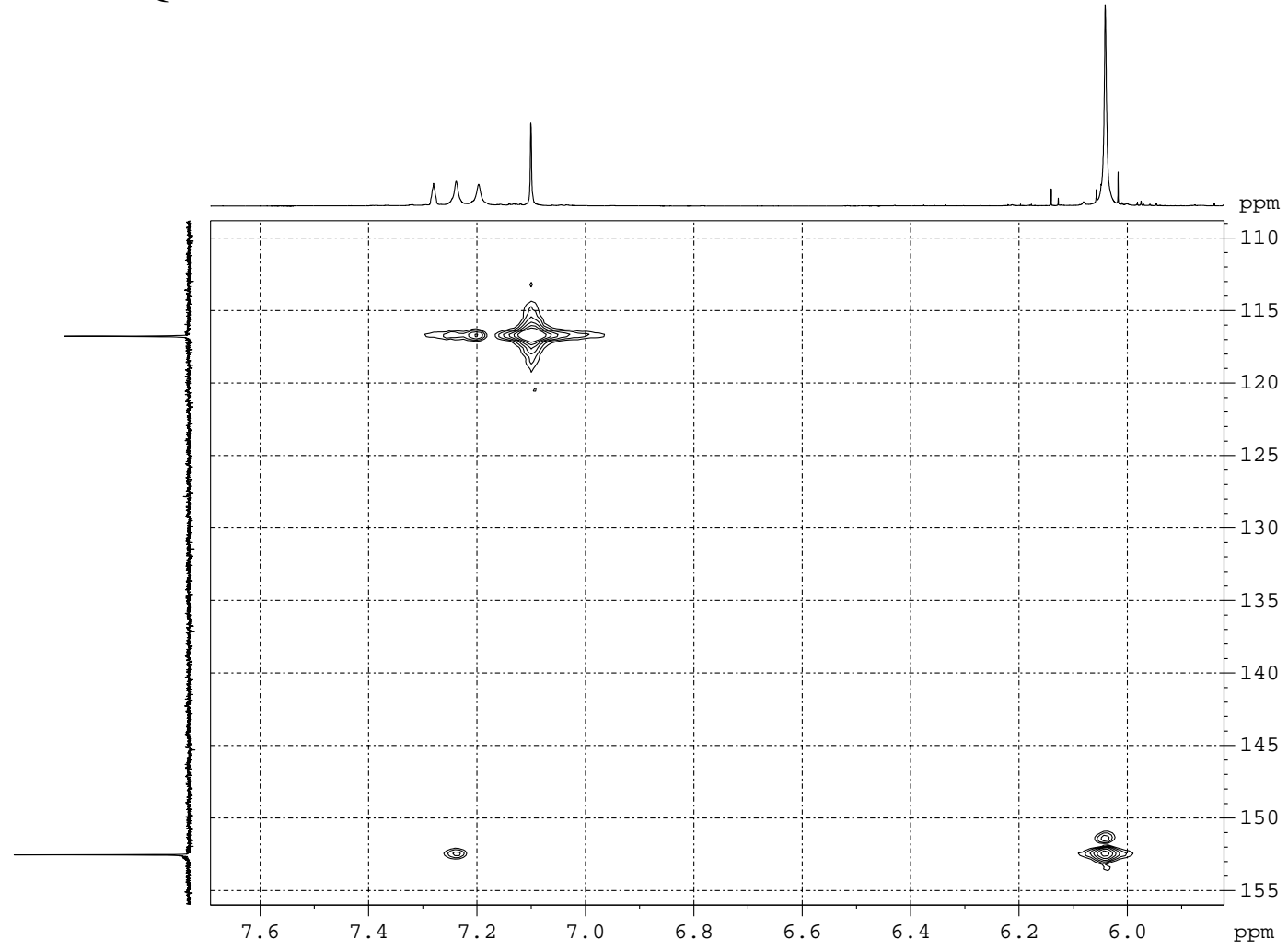


${ }^{1} \mathrm{H}$ NMR of 3

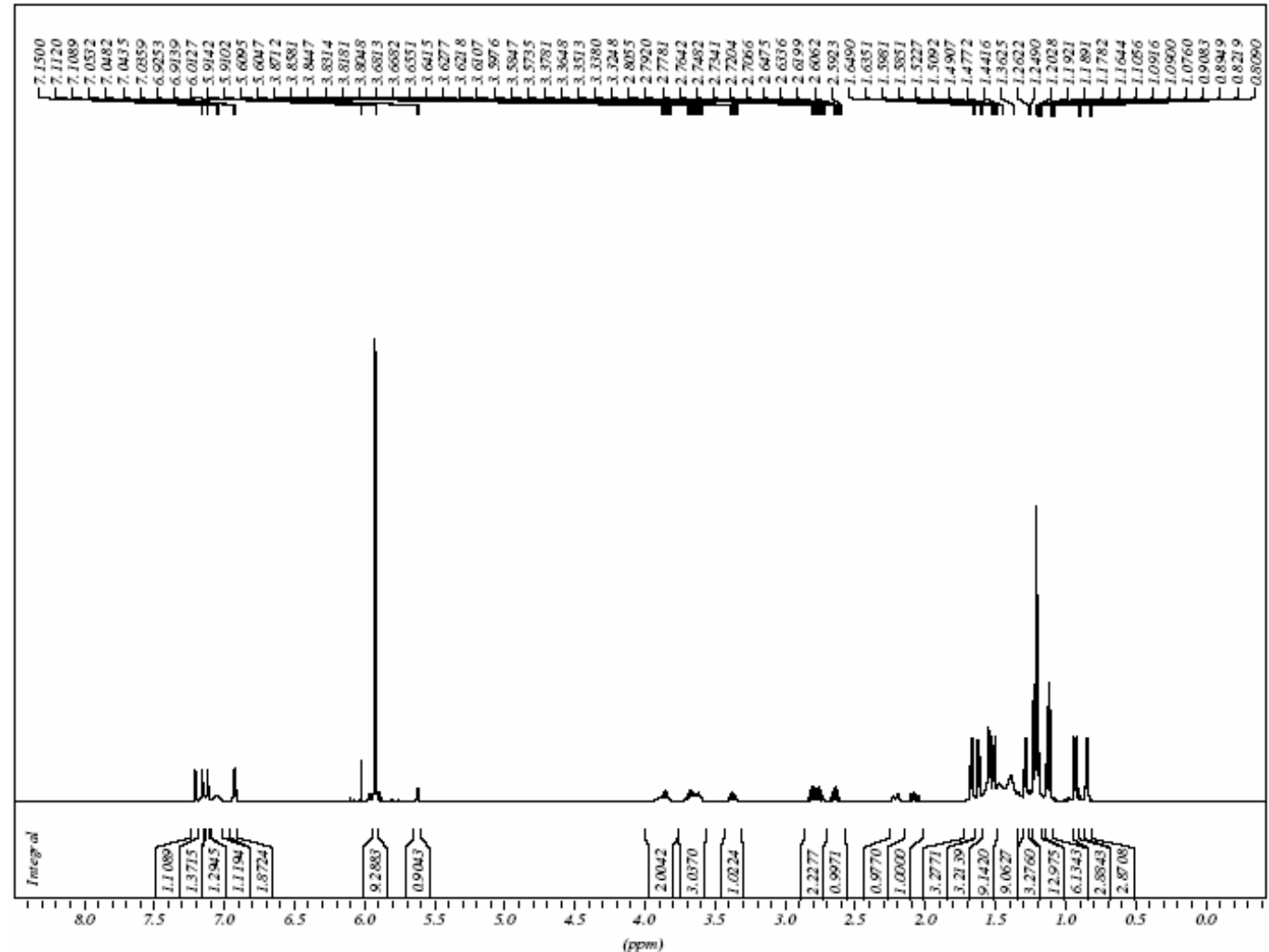

${ }^{1} \mathrm{H}$ NMR of 3

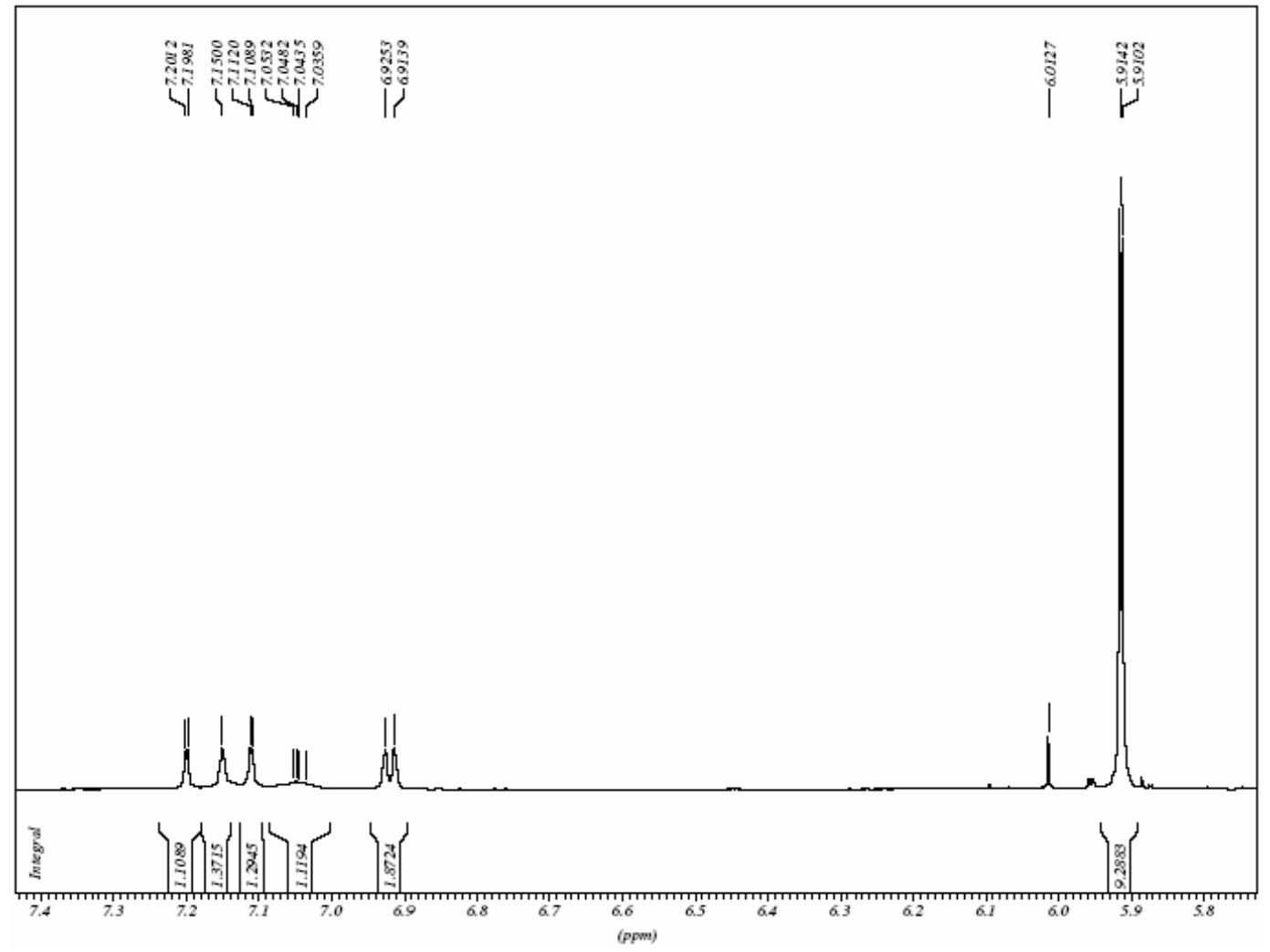


${ }^{1} \mathrm{H}$ NMR of $\mathbf{3}$

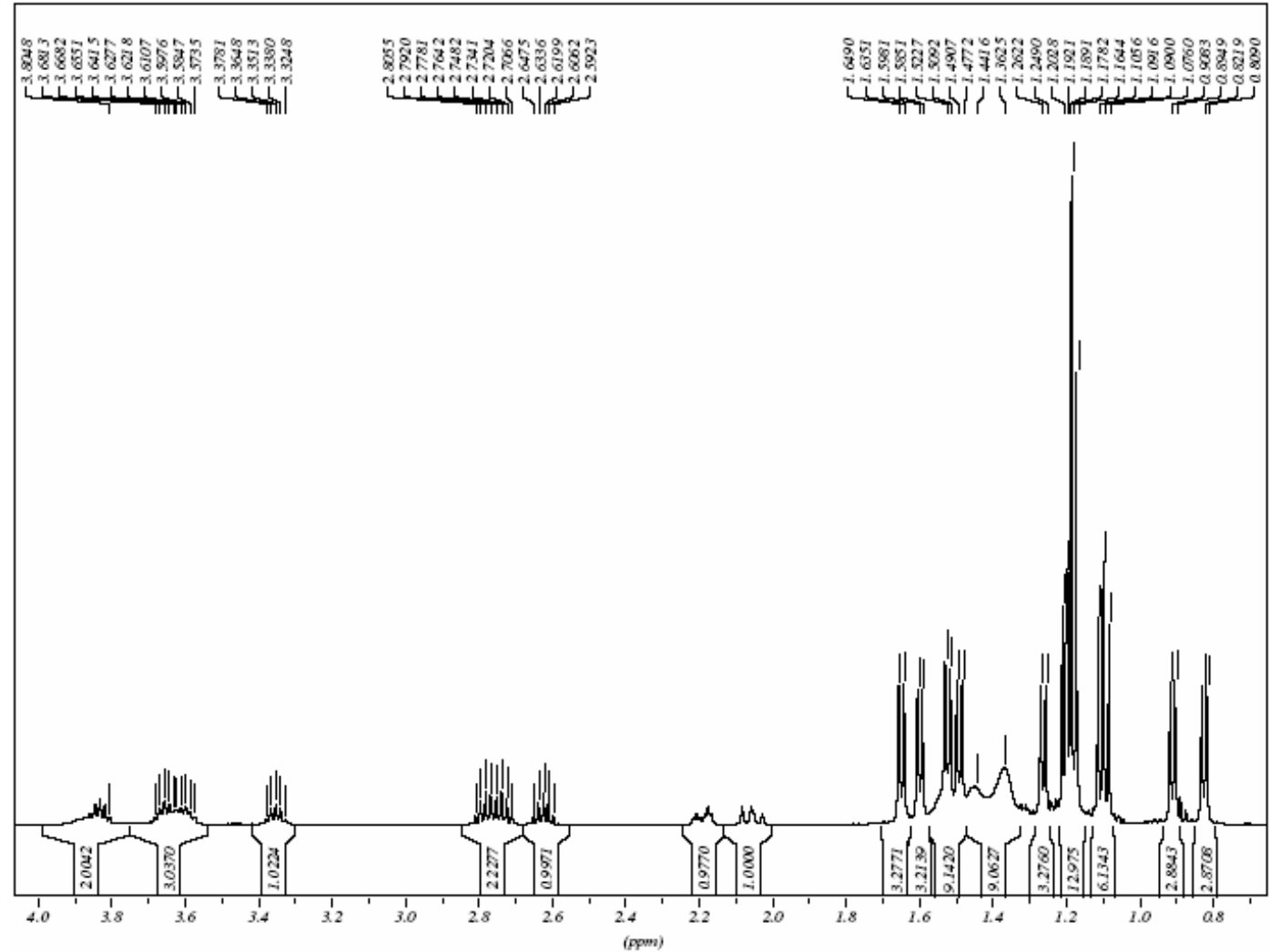

${ }^{13} \mathrm{C}$ NMR of 3

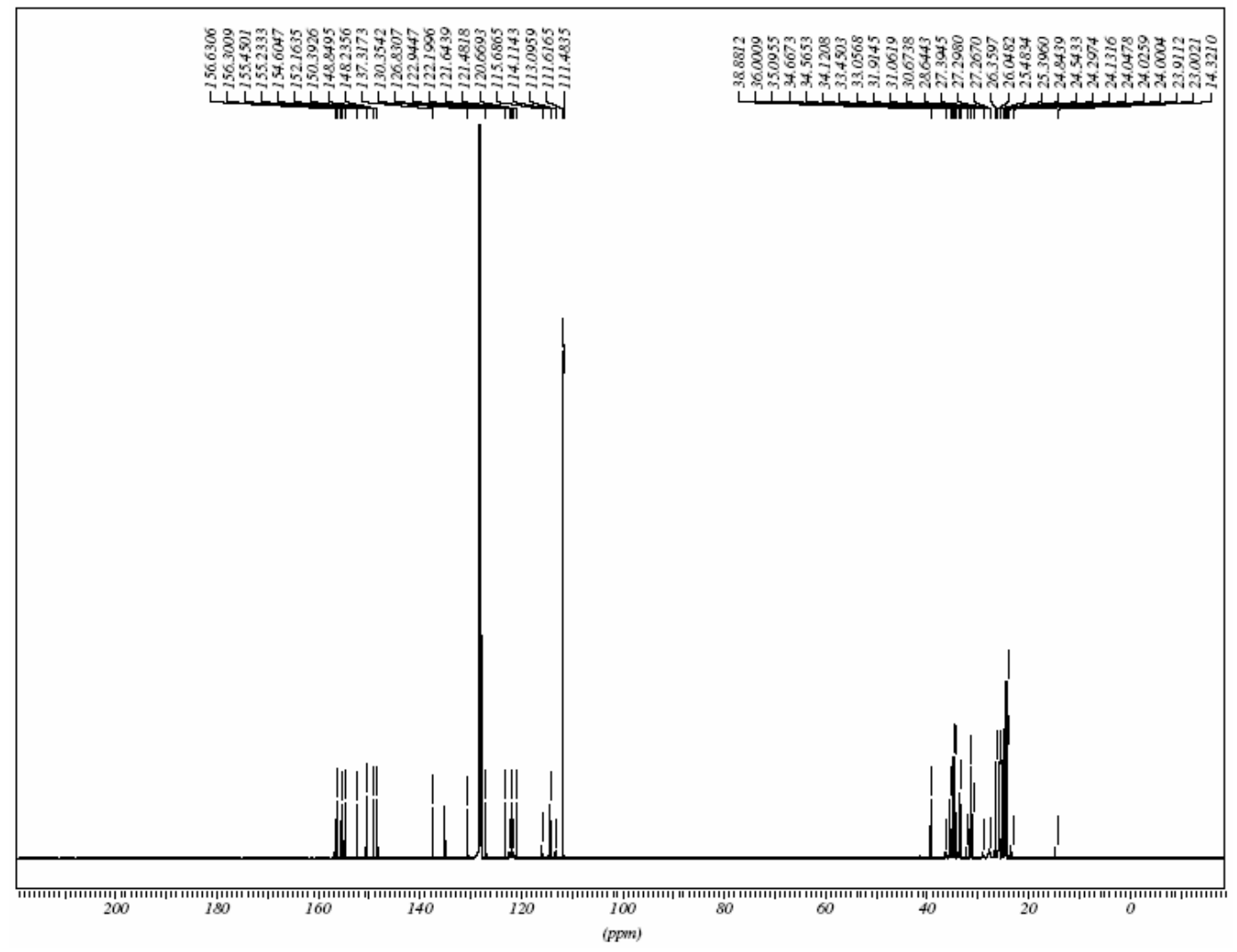




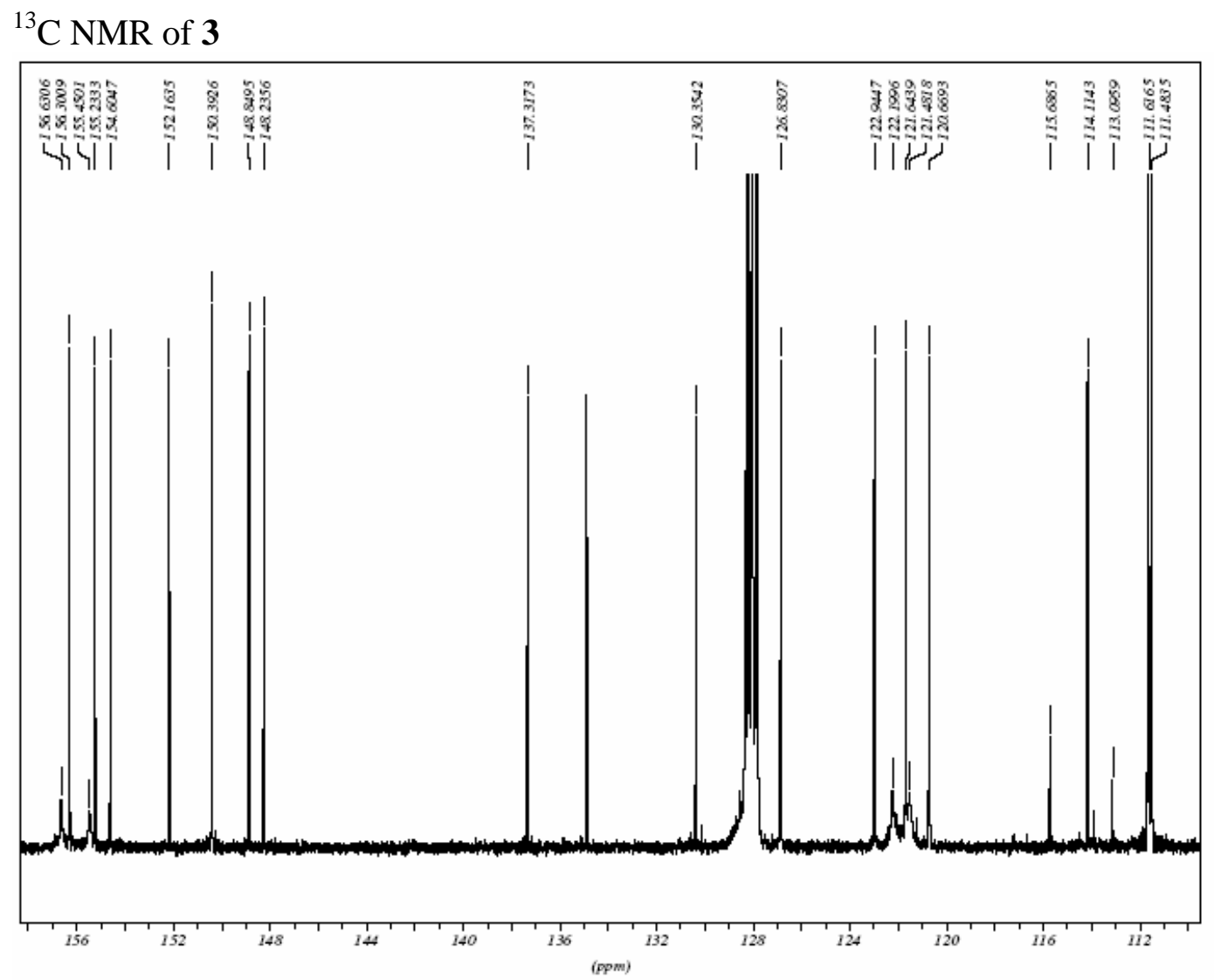

${ }^{13} \mathrm{C}$ NMR of 3

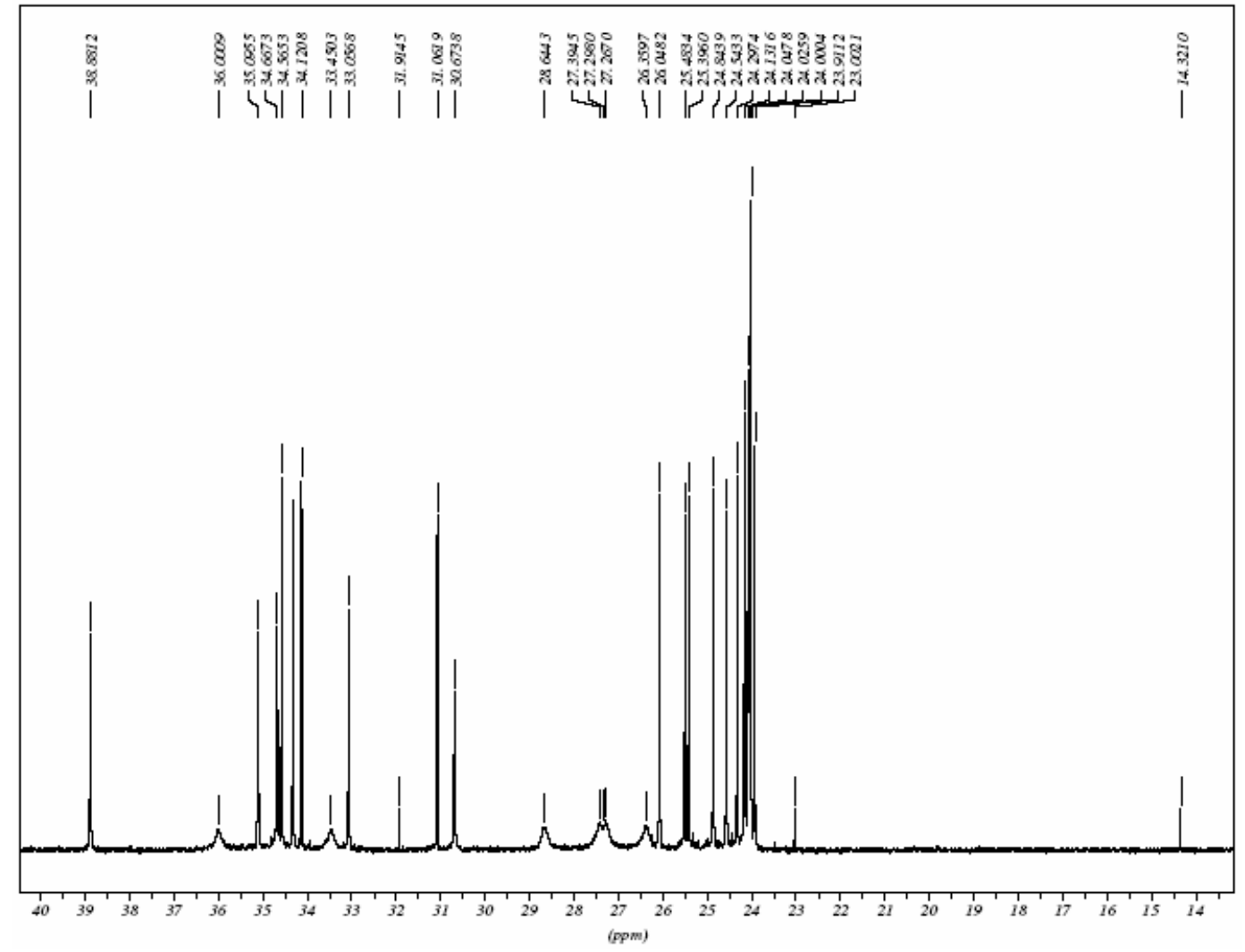


${ }^{29}$ Si NMR of 3

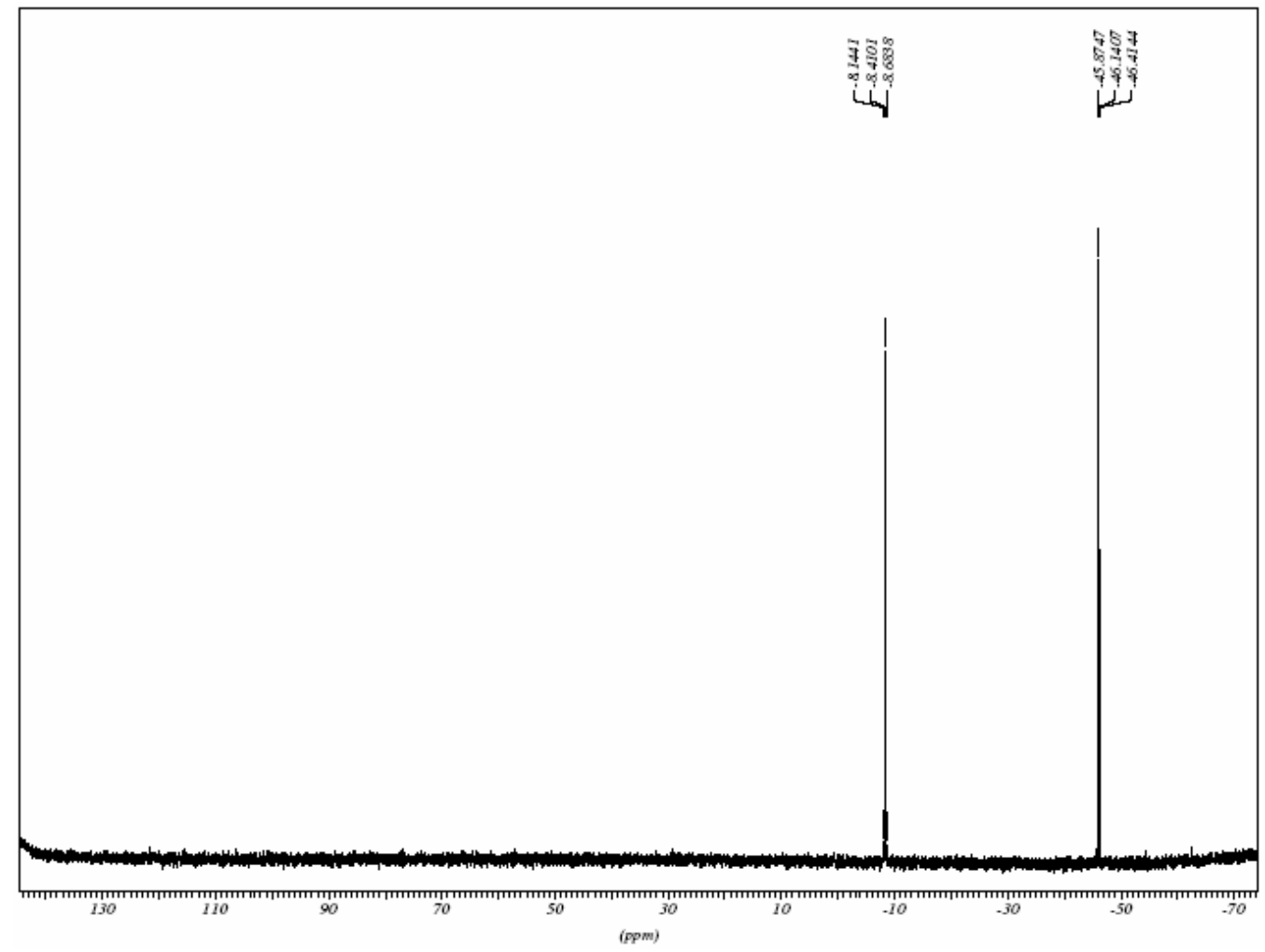

${ }^{29} \mathrm{Si} \mathrm{HMQC} \mathrm{of} \mathrm{3,} \mathrm{D2}=0.5 * 7.5 \mathrm{~Hz}$

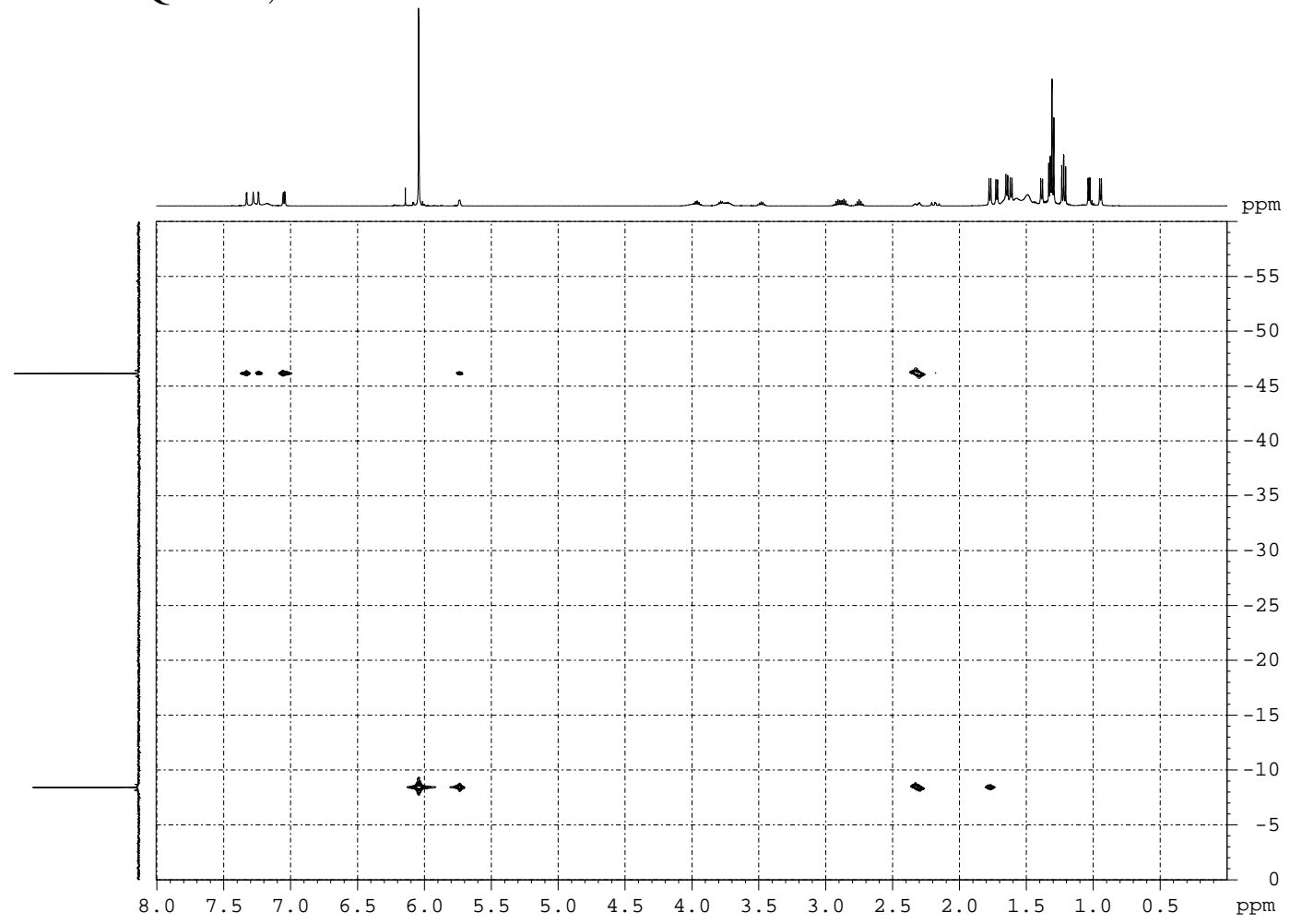


${ }^{29}$ Si HMQC of 3, D2 $=0.5 * 250 \mathrm{~Hz}$

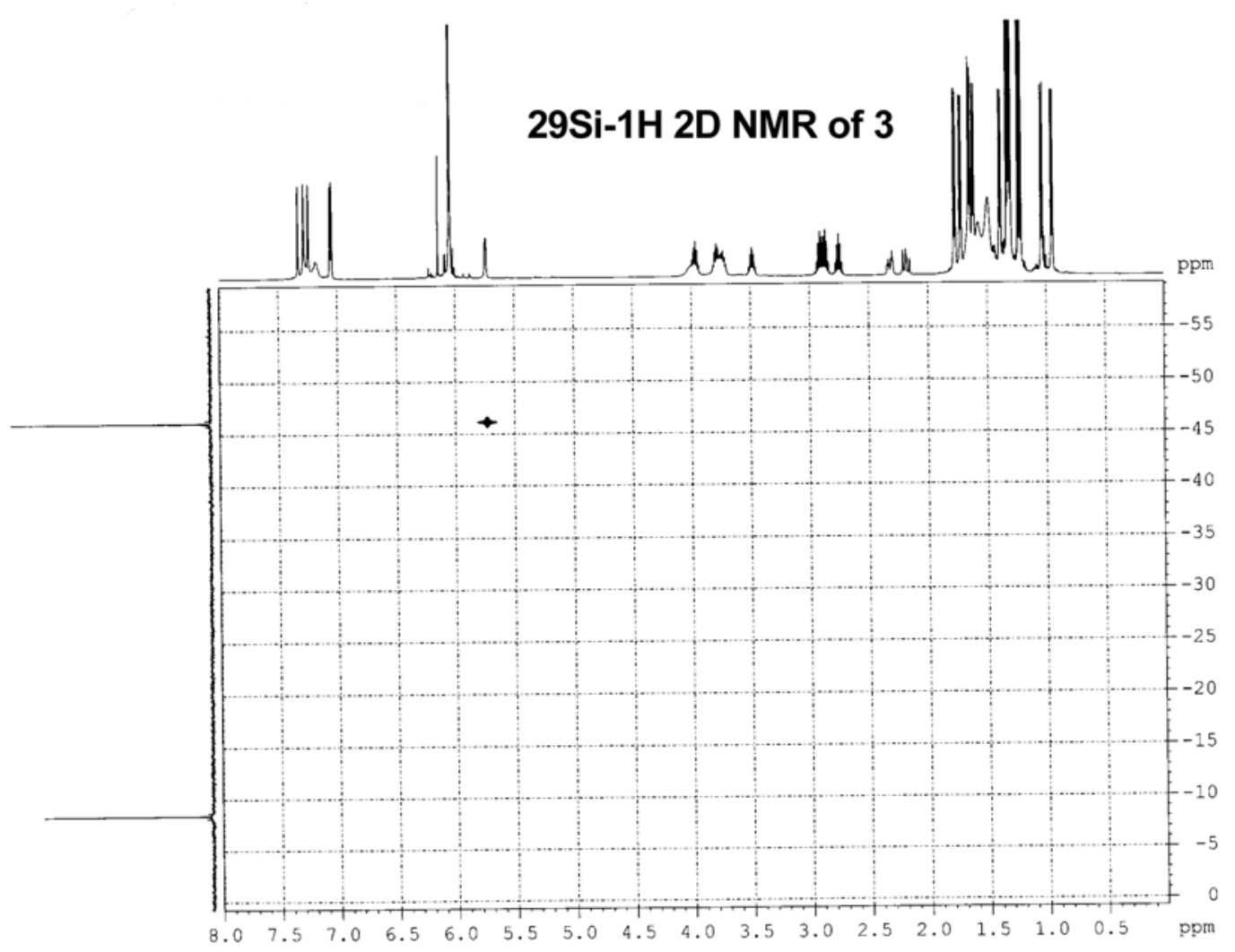

